Research Article

\title{
Port Safety Assessment based on Entropy Weight Matter-Element model
}

Fu Haiwei ${ }^{1, *}$

${ }^{1}$ International Port \& Logistics Research Center, Ningbo University of Technology, Ningbo 315211, China

Received 28 April 2017; Accepted 17 September 2017

\begin{abstract}
Frequently port safety accidents have resulted in port safety problems becoming the focus of increasing attention. Port safety assessment is an important basis in preventing port safety accidents. Owing to complicated influencing factors of port safety, assessing port safety effectively has been a key research topic in the industry and academe. To determine port safety assessment indexes reasonably and acquire practical assessment results, the port safety assessment index system based on 5M (man, machine, material, management, and milieu) was established first. Then, weights of all assessment indexes were determined by the entropy weight method, and the port safety assessment model was constructed by matterelement theory. Finally, the assessment model was verified by ports in Zhejiang Province of China. Results demonstrate that the material factor presents the highest average weight among all evaluation indexes. The accident rate of goods and qualified rate of pollution control are two indexes with the highest weights. The port safety assessment results based on the entropy weight matter-element model conform to practical situations. Thus, the port safety assessment model based on entropy weight matter-element theory can measure port safety level effectively and evaluate its feasibility in practical cases. The model offsets shortcomings of single theory assessment and provides a new idea and decision-making method for port safety assessment.
\end{abstract}

Keywords: port safety, entropy weight, matter-element, assessment, 5M

\section{Introduction}

As an important part of transportation infrastructure, ports are important in international trade transportation [1]. Port safety accidents occur frequently and represent considerable threats to global trade and economic stability [2]. For example, the explosive accident at the wharf in Binhai New Area of Tianjin (China) in 2015 caused 165 deaths and destroyed 304 buildings, thereby resulting in a direct economic loss of CNY 6.866 billion. Port safety refers to a state free from risks from damage to life, property, and environment damage during port operations. Port safety is sensitive to hardware factors (e.g., port facilities and equipment), human factors (e.g., operation and management) and natural factors (e.g., climate and environment). Complicated relationships occur among different factors [3]. Port safety assessment identifies and analyzes risks and harmful factors in port systems by using safety system engineering principles and methods. The assessment also judges the possibility and severity of port safety accidents. Scientific port safety assessment is an important means to prevent port safety accidents and effectively avoid damage to ports, ships, goods, and personnel.

Most existing studies on port safety evaluation have focused on ship navigation and security [4], but a few of them have focused on systematic study that involves personnel, management, and environment. In addition,

*E-mail address: richard_0518@hotmail.com

ISSN: 1791-2377 @ 2017 Eastern Macedonia and Thrace Institute of Technology. All rights reserved. doi:10.25103/iestr.105.04 analytic hierarchy process (AHP), fuzzy comprehensive evaluation, gray evaluation, expert system, and statistical analysis present certain limitations in port safety assessment because of the complicated relationships of assessment indexes [5]. Developing a qualitative and quantitative comprehensive assessment approach, which can solve the multi-property and incompatibility, is needed. Thus, this study attempted to establish a port safety assessment index system from a comprehensive perspective of multiple factors and construct a port safety evaluation model based on entropy weight and matter-element extension theory. Research conclusions are conducive to improving quality of port safety evaluation and present important practical significance.

\section{State of the art}

Analysis of port safety has been a key research field in academic and business circles. Yeo et al. [6] analyzed the relationship between port safety level and container transport by using system dynamics. On the basis of simulations of basic, optimistic, and pessimistic scenes, they found that high economic benefits can be gained by maintaining a low safety level. Port safety is considered an important analysis index, but this aspect is not elaborated thoroughly. Motter and Marta Santos [7] analyzed the effects of communication state on health and safety of port personnel through a semistructured interview. The case study of ports in north Portugal found that the communication mode varies with working pressure and functional division. On the basis of statistics of occupational injuries in Italian ports from 1980 
to 2006, Fabiano et al. [8] discussed the relationship of work organization, working experience, productivity, and occupational accidents. They found that the growth of inexperienced workers can significantly increase risks of occupational injury. These studies have emphasized the influences of human factors on dockworker safety but have neglected other important influencing factors of port safety, such as machine, milieu, and management. On the basis of the review of related port laws and regulations as well as feedback opinions of involved parties of port and navigation, Antão et al. [9] carried out a statistical analysis on indexes, which were used in 526 ports, and constructed regional port indexes, including occupational health, safety, security, and environment. Given that port safety indexes mainly emphasize on safety of ship's navigation, the proposed index system exhibits certain shortcomings in port safety evaluation. In summary, these works have ignored man, machine, material, management, and milieu comprehensively when selecting port safety assessment indexes, thereby resulting in incomprehensiveness of index design.

With respect to port safety assessment approaches, Pak et al. [10] analyzed port safety data, which were collected by 21 captains, by using fuzzy AHP and sorted safety levels of ports in South Korea from the perspective of captains. Fuzzy AHP determines the weights of indexes on the basis of the subjective judgment of experts and scholars, thereby resulting in strong subjectivity of evaluation results. Yang et al. [11] quantitatively analyzed safety of port facilities by a new fuzzy evidence reasoning method. The safety risks of port facilities can be quantified by fuzzy evidence reasoning, which is beneficial to analyze cost effectiveness of port safety control measures. Nevertheless, such an assessment method easily causes certain loss of uncertainty information.

Considering the shortcomings of existing studies, a port safety assessment index system based on the $5 \mathrm{M}$ model was established. Weights of all indexes were determined by entropy weight method. Port safety was evaluated by the matter-element model. When determining weights of indexes, the entropy weight method reduces human interference caused by subjective judgment as much as possible. Matter-element theory is effective at conversion of incompatibility problems into compatibility problems, thereby increasing effectiveness of port safety assessment.

In this study, Section 3 introduces the port safety assessment index system based on the $5 \mathrm{M}$ model and constructs a port safety assessment model based on entropy weight matter-element theory. Section 4 verifies the model through a case study and analyzes research results. Section 5 presents the conclusions of the study.

\section{Methodology}

\subsection{Port safety assessment index system based on $5 \mathrm{M}$ model}

Establishing a reasonable port safety assessment index system is the basis for port safety assessment. Port safety management is a comprehensive system composed of man, machine, and milieu. It includes hardware and software safety managements. On the basis of considerable related literature, the $5 \mathrm{M}$ model in quality management theory was used to establish the port safety assessment system in the current study. Specific assessment indexes were designed from the $5 \mathrm{M}$ perspectives. The $5 \mathrm{M}$ model for port safety assessment is shown in Fig. 1.

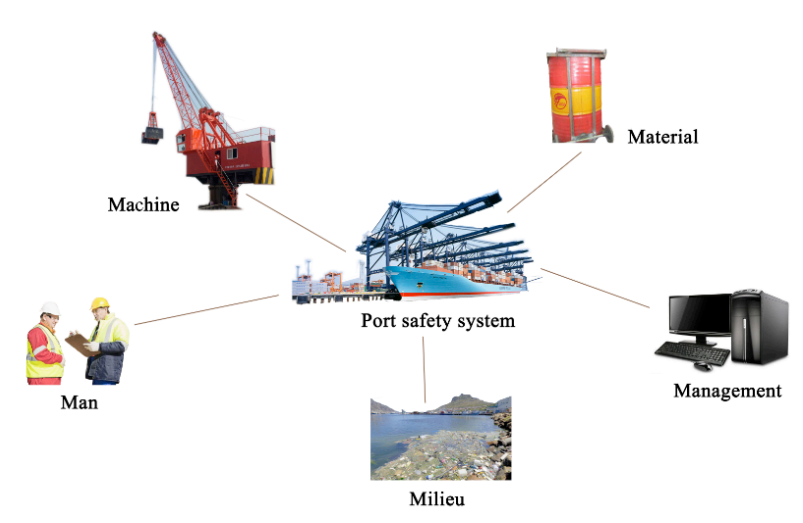

Fig. 1. Port safety assessment system based on 5M model

According to the index system of the $5 \mathrm{M}$ model and related studies, specific indexes of five factors in the $5 \mathrm{M}$ model can be further determined as detailed below.

(1) Man factor (B1) refers to factors related to personnel of port production operation. Specific indexes are proportions of professional certifications (A1), average working years (A2), and average safety training time (A3). The proportion of professional certifications reflects knowledge capacity of port staff. Causing mistakes in port management and operation without related occupational training is extremely simple [12]. The average working years are indicative of operation proficiency of workers. Experienced workers can easily cope with sudden safety accidents, thereby preventing possible accident losses [13]. Average safety training time is indicative of familiarity of workers with safety problems. Planned safety training can enhance safety consciousness of workers [14].

(2) Machine factor (B2) refers to factors related to machine and tools. Specific indexes include adequacy of port facilities (A4), maintenance rate of port facilities (A5), and update rate of port facilities (A6). High adequacy of port facilities can result in improved safeguarding of smooth port production and decreased probability of port accidents [15]. High maintenance rate in port facilities implies high severity of port safety issues and high accident risk. High update rate of port facilities can avoid potential safety risks caused by faults in old equipment [16].

(3) Material factor (B3) refers to factors related to goods and their storage and package. Specific indexes are perfectness ratio of package (A7), accident rate of goods (A8), and qualified rate of storage conditions (A9). Perfectness ratio of package can reduce risks of good damage and leakage. Accident rate of goods can reflect the goods transportation safety level of port [17]. Good storage conditions and standard storage methods can reduce safety risks of special goods [18].

(4) Management factor (B4) refers to factors related to port safety management measures and institutions. Specific indexes are safety risk assessment cycle (A10), perfectness ratio of safety management system (A11), and number of emergency plans (A12). The safety risk assessment cycle is negatively correlated with the perfectness ratio of port safety facilities but is positively related to probability of safety accidents [19]. An improvement in safety management system can clarify division of responsibility and simplify safety management [20]. An increase in emergency plans can reduce or save losses upon accidents [21].

(5) Milieu factor (B5) refers to factors related to infrastructure, natural conditions, and pollution. Specific indexes are utilization rate of port (A13), number of 
abnormal weather days (A14), qualification rate of pollution control (A15), and perfectness ratio of port safety signs (A16). Frequent use of ports can cause heavy load, which can easily cause staff fatigue and equipment fault, thereby causing safety accidents [22]. Abnormal weather results in safety problems. For example, operation in foggy days increases operation difficulty [23]. Port pollution affects the environment and heath conditions of operators [24]. Standard distribution of port safety signs can provide alarms to port staff and reduce probability of safety accidents [25].

From the analysis above, the influencing factor set of port safety can be determined and the port safety assessment index system can be constructed (Fig. 2).

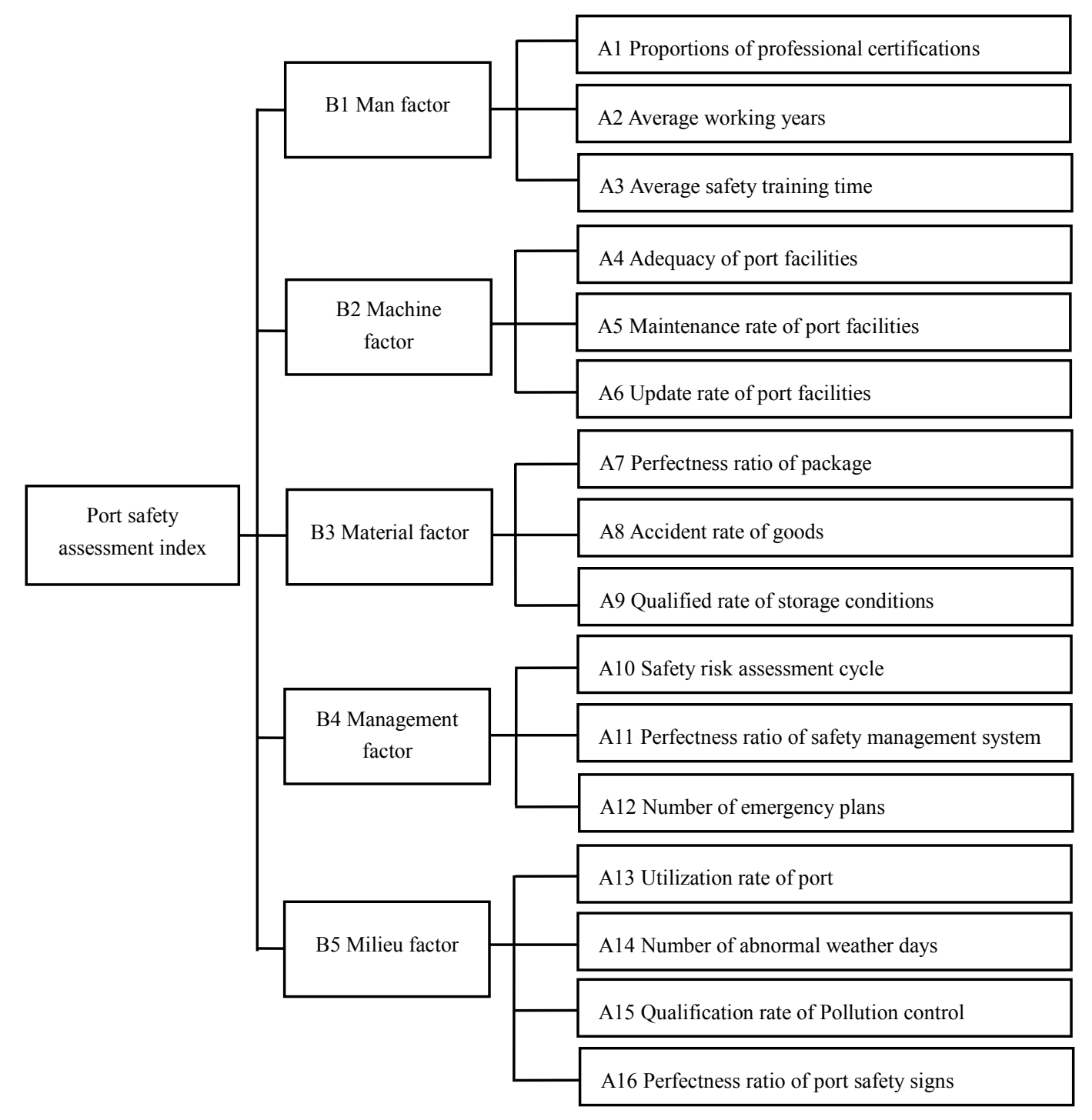

Fig. 2. Port safety assessment index system

\subsection{Port safety assessment model based on entropy weight matter-element theory}

Matter-element theory uses the ordered triad that is composed of matter, feature, and magnitude as the basic elements of description; this way results in matter-element conversion based on extensibility of matter-elements, thereby solving conflicts [26]. The matter-element assessment model can be constructed by using the correlation between matter-element and evaluation level, which can be used for effective assessment of port safety. The computation and assessment procedures are introduced as follows:

Step 1) Matter-elements of port safety are determined.
We suppose $m$ ports that need to be assessed and $n$ indexes that influence port safety. Therefore, port safety can be described by the following $n$-dimensional matterelement:

$$
R=(N, S, Z)=\left[\begin{array}{lll}
N_{i} & s_{1} & z_{i 1} \\
& s_{2} & z_{i 2} \\
\vdots & \vdots \\
& s_{n} & z_{i n}
\end{array}\right]=\left[\begin{array}{l}
W_{1} \\
W_{2} \\
W_{3} \\
W_{4}
\end{array}\right]
$$

where $R$ is the $n$-dimensional matter-element for port safety assessment, $N_{i} \quad(i=1,2, \cdots, m)$ is the $i$ th port, $S_{k}(k=1,2, \cdots, n)$ is the $k$ th index that influences port safety, 
and $z_{i k}$ is the magnitude of the $i$ th port in relative to the influencing index $k$.

Step 2) Classical domain $\left(R_{0}\right)$, node domain $\left(R_{p}\right)$, and assessing matter-element $\left(R_{m}\right)$ are determined.

According to standards of port safety leveling, if $y$ port safety levels are present, then the classical matter-element of the research object in the matter-element system is $R_{0 j}=\left(N_{0 j}, S, Z_{0 j}\right)$ :

$$
R_{0 j}=(N, S, Z)=\left[\begin{array}{ccc}
N_{0 j} & s_{1} & z_{0 j 1} \\
& s_{2} & z_{0 j 2} \\
& \vdots & \vdots \\
& s_{n} & z_{0 j n}
\end{array}\right]=\left[\begin{array}{ccc}
N_{0 j} & s_{1} & \left(a_{0 j 1}, b_{0 j 1}\right) \\
& s_{2} & \left(a_{0 j 2}, b_{0 j 2}\right) \\
& \vdots & \vdots \\
& s_{n} & \left(a_{0 j n}, b_{0 j n}\right)
\end{array}\right](2)
$$

where $N_{0 j}$ is type $j \quad(j=1,2, \cdots, y)$ in the port safety system and $z_{0 j k}$ is the magnitude domain of index $k$ in the level $j$ after specification.

The bottom-up order of value ranges of all indexes is the matter-element of node domain $R_{p}=\left(N_{p}, S, Z_{p}\right) . N_{p}$ is all port safety levels in the matter-element system and $z_{p k}$ is the value domain of feature $s_{k}$; that is, the node domain of $N_{p}$.

$$
R_{p}=\left[\begin{array}{ccc}
N_{p} & s_{1} & z_{p 1} \\
& s_{2} & z_{p 2} \\
\vdots & \vdots \\
& s_{n} & z_{p n}
\end{array}\right]=\left[\begin{array}{ccc}
N_{p} & s_{1} & \left(a_{p 1}, b_{p 1}\right) \\
& s_{2} & \left(a_{p 2}, b_{p 2}\right) \\
& \vdots & \vdots \\
& s_{n} & \left(a_{p n}, b_{p n}\right)
\end{array}\right]
$$

We determine the assessing matter-element $R_{m}$. For the assessing port, the assessment information that is collected by the port $m$ can be expressed by matter-element. The assessing matter-element is as follows:

$$
R_{m}=\left[\begin{array}{ccc}
N_{m} & s_{1} & z_{m 1} \\
& s_{2} & z_{m 2} \\
\vdots & \vdots \\
& s_{n} & z_{m n}
\end{array}\right]
$$

where $N_{m}$ is the port $m, s_{k}$ is the index $k(k=1,2, \cdots, n)$ that influences port safety, and $z_{m k}$ is the value of the port $m$ in relative to index $k$.

Step 3) Nondimensionalization of indexes.

Given that assessment indexes present different dimensions, which is inconvenient for statistics, nondimensionalization of indexes is needed. The processing method is as follows:

$\bar{z}_{m k}=\left\{\begin{array}{l}\frac{z_{m k}-z_{k}^{\min }}{z_{k}^{\max }-z_{k}^{\min }} \text { For the larger the better indicators } \\ \frac{z_{k}^{\max }-z_{m k}}{z_{k}^{\max }-z_{k}^{\min }} \text { For the smaller the better indicators }\end{array}\right.$ where $\bar{z}_{m k}$ is the evaluation value of index $k$ of port $m$ after nondimensionalization, $z_{m k}$ is the evaluation value of index $k$ of port $m$ before nondimensionalization, $z_{k}^{\max }$ is the maximum evaluation value of index $k$, and $z_{k}^{\min }$ is the minimum evaluation value of index $k$.

Step 4) Correlation function of port safety assessment indexes is calculated.

The correlation function between index $k$ of port $m$ and the port safety category $j$ is

$r_{i j}\left(z_{i k}\right)=\left\{\begin{array}{c}\frac{-\rho\left(z_{i k}, z_{0 j k}\right)}{\left|z_{0 j k}\right|}, z_{i k} \in z_{0 j k} \\ \frac{\rho\left(z_{i k}, z_{0 j k}\right)}{\rho\left(z_{i k}, z_{p k}\right)-\rho\left(z_{i k}, z_{0 j k}\right)}, z_{i k} \notin z_{0 j k}\end{array}\right.$

where $i=1,2, \cdots, m, j=1,2, \cdots, y$ and $k=1,2, \cdots, n$.

$$
\begin{aligned}
& \rho\left(z_{i k}, z_{0 j k}\right)=\left|z_{i k}-\frac{1}{2}\left(a_{0 j k}+b_{0 j k}\right)\right|-\frac{1}{2}\left(b_{0 j k}-a_{0 j k}\right) \\
& \rho\left(z_{i k}, z_{p k}\right)=\left|z_{i k}-\frac{1}{2}\left(a_{p k}+b_{p k}\right)\right|-\frac{1}{2}\left(b_{p k}-a_{p k}\right)
\end{aligned}
$$

Equations (7) and (8) indicate the concept of distance that is introduced by matter-element theory.

Step 5) Weight coefficient by entropy weight method is determined.

Entropy weight reflects the useful information size that is provided by indexes to decision evaluation. Information utility value of $n$ evaluation indexes is measured by entropy, thereby enabling the determination of entropy weight of indexes. Specific steps are as follows:

We suppose that the assessing port is divided into $y$ levels. Each level possesses $n$ evaluation indexes with the constructed judgment matrix $R$. This matrix is the correlation coefficient matrix that is determined in the previous step:

$$
R=\left(r_{i j}\right)_{y \times n}(i=1,2, \cdots, y, j=1,2, \cdots, n)
$$

The judgment matrix $R$ is normalized, thereby obtaining the normalized matrix.

From the traditional concept of entropy, entropies of different assessment indexes can be defined as follows:

$$
\begin{aligned}
& H_{j}=\frac{-1}{\ln y} \sum_{i=1}^{y} f_{i j} \ln f_{i j}(i=1,2, \cdots, y, j=1,2, \cdots, n) \\
& f_{i j}=r_{i j} \sum_{i=1}^{y} r_{i j}
\end{aligned}
$$

Entropy weights of different assessment indexes $W$ are calculated. 


$$
W=\left(\omega_{j}\right)_{1 \times n}=\frac{1-H_{j}}{n-\sum_{j=1}^{n} H_{j}}, \text { and } \sum_{j=1}^{n} \omega_{j}=1
$$

Step 6) Correlation of port safety categories is determined.

The correlation between matter-element $N_{i}$ of port and the level $t$ is as follows:

$$
\begin{aligned}
& k_{i t}\left(N_{i}\right)=\sum \omega_{j} r_{i t}\left(z_{i j}\right) \\
& k_{i t 0}=\max \left\{k_{i t}\left(N_{i}\right), t=1,2, \cdots, c\right\}
\end{aligned}
$$

Step 7) The port safety level of $N_{i}$ can be determined $t_{0}$ in accordance with Equation (14).

\section{Result Analysis and Discussion}

A case study of ports in Zhejiang Province of China was carried out to explain applications of the entropy weight matter-element model in port safety assessment. Numerous ports are present in the study area. Owing to different construction times and geological locations, the port safety management varies. Five representative ports were chosen for field investigation from May 2017 to June 2017. Related data were acquired by visiting the Zhejiang Port and Navigation Authority. Safety models of these five ports were evaluated on the basis of the collected data.

\subsection{Nondimensionalization and grading of port safety indexes}

Port safety is divided into five levels (I-V). I is the best and $\mathrm{V}$ is the worst. Grading of port safety assessment indexes after nondimensionalization is shown in Table 1. Safety levels are divided following the International Ship and Port Facility Security Code that was issued by IMO, Safety and Health in Ports that was issued by ILO, and suggestions of five authority experts from Dalian Maritime University, Shanghai Maritime University, and port enterprises. We interviewed experts via e-mail, telephone, and video conference in June 2017. We summarized the interview results. The nondimensionalization results of safety indexes of five representative ports based on the collected data are

\begin{tabular}{|c|c|c|c|c|c|c|}
\hline \multirow{2}{*}{\multicolumn{2}{|c|}{ Factor and index }} & \multicolumn{5}{|c|}{ Level } \\
\hline & & \multirow{2}{*}{$\begin{array}{c}\mathrm{I} \\
(0.72,1.00) \\
(0.84,1.00) \\
(0.85,1.00)\end{array}$} & \multirow{2}{*}{$\begin{array}{c}\text { II } \\
(0.55,0.72) \\
(0.67,0.84) \\
(0.80,0.85)\end{array}$} & \multirow{2}{*}{$\begin{array}{c}\text { II } \\
(0.36,0.55) \\
(0.51,0.67) \\
(0.70,0.80)\end{array}$} & \multirow{2}{*}{$\begin{array}{c}\text { IV } \\
(0.12,0.36) \\
(0.30,0.51) \\
(0.60,0.70)\end{array}$} & \multirow{2}{*}{$\begin{array}{c}\mathrm{V} \\
(0.00,0.12) \\
(0.00,0.30) \\
(0.00,0.60) \\
\end{array}$} \\
\hline Man & $\begin{array}{l}\text { Proportion of professional certifications } \\
\text { Average working years } \\
\text { Average safety training time }\end{array}$ & & & & & \\
\hline Machine & $\begin{array}{l}\text { Adequacy of port facilities } \\
\text { Maintenance rate of port facilities } \\
\text { Update rate of port facilities }\end{array}$ & $\begin{array}{l}(0.92,1.00) \\
(0.91,1.00) \\
(0.82,1.00) \\
\end{array}$ & $\begin{array}{l}(0.80,0.92) \\
(0.78,0.91) \\
(0.62,0.82) \\
\end{array}$ & $\begin{array}{l}(0.63,0.80) \\
(0.65,0.78) \\
(0.55,0.62) \\
\end{array}$ & $\begin{array}{l}(0.30,0.63) \\
(0.48,0.65) \\
(0.45,0.55) \\
\end{array}$ & $\begin{array}{l}(0.00,0.30) \\
(0.00,0.48) \\
(0.00,0.45) \\
\end{array}$ \\
\hline Material & $\begin{array}{l}\text { Perfectness ratio of package } \\
\text { Accident rate of goods } \\
\text { Qualified rate of storage conditions }\end{array}$ & $\begin{array}{l}(0.94,1.00) \\
(0.91,1.00) \\
(0.94,1.00) \\
\end{array}$ & $\begin{array}{l}(0.90,0.94) \\
(0.78,0.91) \\
(0.90,0.94) \\
\end{array}$ & $\begin{array}{l}(0.85,0.90) \\
(0.65,0.78) \\
(0.85,0.90) \\
\end{array}$ & $\begin{array}{l}(0.70,0.85) \\
(0.48,0.65) \\
(0.70,0.80) \\
\end{array}$ & $\begin{array}{l}(0.00,0.70) \\
(0.00,0.48) \\
(0.00,0.70) \\
\end{array}$ \\
\hline Management & $\begin{array}{l}\text { Safety risk assessment cycle } \\
\text { Perfectness ratio of safety management system } \\
\text { Number of emergency plans }\end{array}$ & $\begin{array}{l}(0.67,1.00) \\
(0.90,1.00) \\
(0.90,1.00) \\
\end{array}$ & $\begin{array}{l}(0.50,0.67) \\
(0.82,0.90) \\
(0.70,0.90) \\
\end{array}$ & $\begin{array}{l}(0.25,0.50) \\
(0.75,0.82) \\
(0.60,0.70) \\
\end{array}$ & $\begin{array}{l}(0.17,0.25) \\
(0.65,0.75) \\
(0.30,0.60) \\
\end{array}$ & $\begin{array}{l}(0.00,0.17) \\
(0.00,0.65) \\
(0.00,0.30) \\
\end{array}$ \\
\hline Milieu & $\begin{array}{l}\text { Utilization rate of port } \\
\text { Number of abnormal weather days } \\
\text { Qualification rate of pollution control } \\
\text { Perfectness ratio of port safety signs }\end{array}$ & $\begin{array}{l}(0.80,1.00) \\
(0.75,1.00) \\
(0.80,1.00) \\
(0.93,1.00)\end{array}$ & $\begin{array}{l}(0.75,0.80) \\
(0.67,0.75) \\
(0.70,0.80) \\
(0.90,0.93)\end{array}$ & $\begin{array}{l}(0.65,0.75) \\
(0.58,0.67) \\
(0.60,0.70) \\
(0.86,0.90)\end{array}$ & $\begin{array}{l}(0.50,0.65) \\
(0.50,0.58) \\
(0.55,0.60) \\
(0.80,0.86)\end{array}$ & $\begin{array}{l}(0.00,0.50) \\
(0.00,0.50) \\
(0.00,0.55) \\
(0.00,0.80)\end{array}$ \\
\hline
\end{tabular}
listed in Table 2.

Table 1. Port safety assessment indexes rating table

\begin{tabular}{|c|c|c|c|c|c|c|}
\hline \multicolumn{2}{|r|}{$\begin{array}{l}\text { Factor and index } \\
\end{array}$} & \multirow{2}{*}{$\begin{array}{l}\text { Port 1 } \\
0.73\end{array}$} & \multirow{2}{*}{$\begin{array}{l}\text { Port 2 } \\
0.63\end{array}$} & \multirow{2}{*}{$\begin{array}{l}\text { Port 3 } \\
0.75\end{array}$} & \multirow{2}{*}{$\begin{array}{l}\text { Port } 4 \\
0.39\end{array}$} & \multirow{2}{*}{$\begin{array}{l}\text { Port } 5 \\
0.15\end{array}$} \\
\hline \multirow{3}{*}{ Man } & Proportion of professional certifications & & & & & \\
\hline & Average working years & 0.96 & 0.74 & 0.82 & 0.81 & 0.54 \\
\hline & Average safety training time & 0.86 & 0.82 & 0.81 & 0.83 & 0.53 \\
\hline \multirow{3}{*}{ Machine } & Adequacy of port facilities & 0.93 & 0.85 & 0.84 & 0.86 & 0.51 \\
\hline & Maintenance rate of port facilities & 0.96 & 0.87 & 0.83 & 0.78 & 0.52 \\
\hline & Update rate of port facilities & 0.82 & 0.67 & 0.67 & 0.64 & 0.53 \\
\hline \multirow{3}{*}{ Material } & Perfectness ratio of package & 0.95 & 0.94 & 0.93 & 0.92 & 0.85 \\
\hline & Accident rate of goods & 0.90 & 0.90 & 0.85 & 0.83 & 0.55 \\
\hline & Qualified rate of storage conditions & 0.95 & 0.95 & 0.93 & 0.89 & 0.78 \\
\hline \multirow{3}{*}{ Management } & Safety risk assessment cycle & 0.75 & 0.68 & 0.75 & 0.63 & 0.23 \\
\hline & Perfectness ratio of safety management system & 0.95 & 0.85 & 0.89 & 0.83 & 0.73 \\
\hline & Number of emergency plans & 0.90 & 0.80 & 0.80 & 0.80 & 0.50 \\
\hline \multirow{4}{*}{ Milieu } & Utilization rate of port & 0.82 & 0.81 & 0.82 & 0.80 & 0.65 \\
\hline & Number of abnormal weather days & 0.75 & 0.70 & 0.62 & 0.63 & 0.42 \\
\hline & Qualification rate of pollution control & 0.86 & 0.76 & 0.82 & 0.83 & 0.55 \\
\hline & Perfectness ratio of port safety signs & 0.95 & 0.93 & 0.92 & 0.89 & 0.58 \\
\hline
\end{tabular}

Table 2. Nondimensionalization results of five ports safety index values

4.2 Classical domain, node domain of port safety matterelement, and the assessing matter-element

Classical domain of matter-element is determined on the basis of the classification of port safety assessment indexes of $\mathrm{I}-\mathrm{V}$ levels in Table 1 . The 16 assessment indexes are denoted as s1-s16. The matter-element of the classical domain is as follows: 


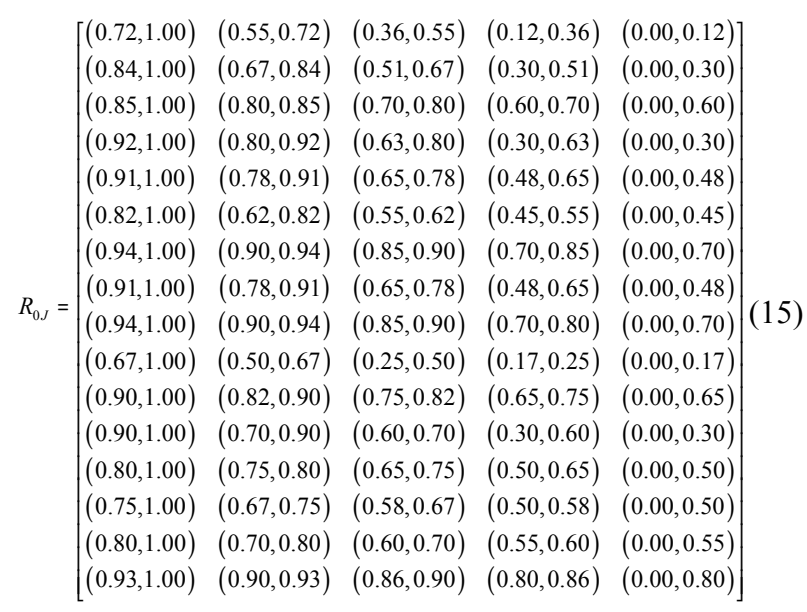

The node domain can be determined from the overall value range of port safety assessment indexes as follows:

$R_{p}=\left[\begin{array}{ccc}N_{p} & s_{1} & z_{p 1} \\ & s_{2} & z_{p 2} \\ \vdots & \vdots \\ & s_{16} & z_{p 16}\end{array}\right]=\left[\begin{array}{ccc}N_{p} & s_{1} & (0.00,1.00) \\ & s_{2} & (0.00,1.00) \\ & \vdots & \vdots \\ & s_{16} & (0.00,1.00)\end{array}\right]$

The assessing matter-element of five ports can be determined as follows from Table 2:

$R_{m 1}=\left[\begin{array}{ccc}N_{1} & s_{1} & 0.73 \\ & s_{2} & 0.96 \\ \vdots & \vdots \\ & s_{16} & 0.95\end{array}\right]$

$R_{m 2}=\left[\begin{array}{ccc}N_{2} & s_{1} & 0.63 \\ & s_{2} & 0.74 \\ & \vdots & \vdots \\ & s_{16} & 0.93\end{array}\right]$

$R_{m 3}=\left[\begin{array}{ccc}N_{3} & s_{1} & 0.75 \\ & s_{2} & 0.82 \\ & \vdots & \vdots \\ & s_{16} & 0.92\end{array}\right]$

$R_{m 4}=\left[\begin{array}{ccc}N_{4} & s_{1} & 0.39 \\ & s_{2} & 0.81 \\ & \vdots & \vdots \\ & s_{16} & 0.89\end{array}\right]$

$R_{m 5}=\left[\begin{array}{ccc}N_{5} & s_{1} & 0.15 \\ & s_{2} & 0.54 \\ & \vdots & \vdots \\ & s_{16} & 0.58\end{array}\right]$

\subsection{Determination of Weight coefficients}

Weight coefficients of different indexes can be calculated by entropy weight method in accordance with Equations (9), (10), (11), and (12) (Table 3).

Table 3. Weight coefficients of port safety assessment index

\begin{tabular}{|c|c|c|}
\hline Factor & Index & $\begin{array}{c}\text { Weight } \\
\text { coefficient }\end{array}$ \\
\hline \multirow{4}{*}{ Man } & $\begin{array}{c}\text { Proportion of professional } \\
\text { certifications }\end{array}$ & 0.050 \\
\hline & Average working years & 0.053 \\
\hline & Average safety training time & 0.063 \\
\hline & $\begin{array}{l}\text { Average weight coefficient of man } \\
\text { indexes }\end{array}$ & 0.055 \\
\hline \multirow{4}{*}{ Machine } & Adequacy of port facilities & 0.051 \\
\hline & Maintenance rate of port facilities & 0.052 \\
\hline & Update rate of port facilities & 0.002 \\
\hline & $\begin{array}{l}\text { Average weight coefficient of } \\
\text { machine indexes }\end{array}$ & 0.035 \\
\hline \multirow{4}{*}{ Material } & Perfectness ratio of package & 0.057 \\
\hline & Accident rate of goods & 0.124 \\
\hline & Qualified rate of storage conditions & 0.056 \\
\hline & $\begin{array}{l}\text { Average weight coefficient of } \\
\text { material indexes }\end{array}$ & 0.079 \\
\hline \multirow{4}{*}{ Management } & Safety risk assessment cycle & 0.074 \\
\hline & $\begin{array}{l}\text { Perfectness ratio of safety } \\
\text { management system }\end{array}$ & 0.061 \\
\hline & Number of emergency plans & 0.065 \\
\hline & $\begin{array}{c}\text { Average weight coefficient of } \\
\text { management indexes }\end{array}$ & 0.067 \\
\hline \multirow{5}{*}{ Milieu } & Utilization rate of port & 0.055 \\
\hline & Number of abnormal weather days & 0.052 \\
\hline & $\begin{array}{c}\text { Qualification rate of pollution } \\
\text { control } \\
\end{array}$ & 0.122 \\
\hline & Perfectness ratio of port safety signs & 0.063 \\
\hline & $\begin{array}{c}\text { Average weight coefficient of milieu } \\
\text { indexes }\end{array}$ & 0.073 \\
\hline
\end{tabular}

Table 3 indicates that weights of accident rate of goods and qualification rate of pollution control are higher than 0.1 . Weights of safety risk assessment cycle, number of emergency plans, average safety training time, perfectness ratio of safety management system, and perfectness ratio of port safety signs range between 0.06 and 0.1 . Weights of the remaining indexes are lower than 0.06. Accident rate of goods and qualification rate of pollution control are the most important influencing indexes of port safety assessment. The order in terms of average weight of factors is as follows: material factor $>$ milieu factor $>$ management factor $>$ man factor $>$ machine factor. In summary, material factor is the most important in port safety management. Enhancing safety treatment of materials is necessary.

\subsection{Port safety assessment results and analysis}

The correlation coefficients of five ports can be calculated in accordance with Equations (13) and (14). The results are evaluated (Table 4). Safety assessment results of five ports and field investigations of port safety management were analyzed as follows.

Port 1 is a listed state-owned enterprise that focuses considerably on port safety management. It possesses adequate facilities, low maintenance rate, and high update rate of port facilities, as well as relatively small potential risk of port production. Meanwhile, most workers not only have long working years and are familiar with machine operation and operation procedures but also have a strong ability to cope with safety accidents. The enterprise also emphasizes on safety education. Port 1 offers long-term training to 
employees to enhance safety consciousness. Therefore, Port 1 is evaluated as having the highest level, that is, level I.

Ports 2, 3, and 4 are evaluated as level II. Port 2 exhibits relatively poor performance in safety risk assessment cycle but presents relatively excellent performance in package and storage of goods and accident management. Port 3 shows prominent performance in safety risk assessment and professional certification but possesses high accident rate of goods. Port 4 exhibits a low proportion of professional certifications but presents enhanced port safety training.

Port 5 is an old port of unsatisfying geological positions and foggy weather. Owing to the low proportion of professional certifications and poor safety risk assessment, frequent accidents of goods occur. Moreover, this port is equipped with poor machine facilities and environmental control measures. It possesses high safety risks and has been asked to undergo rectification by port administration departments several times. This port is beginning internal restructuring and plans to change its existing safety status.

Table 4. Safety categories correlation and assessment results of five ports

\begin{tabular}{c|c|c|c|c|c|c}
\hline \multirow{2}{*}{ Port } & \multicolumn{5}{|c|}{ Level } & \multirow{2}{*}{$\begin{array}{c}\text { Assessment } \\
\text { results }\end{array}$} \\
\cline { 2 - 6 } & I & II & III & IV & V & \\
\hline Port1 & 0.1675 & -0.0366 & -0.5375 & -0.6257 & -0.7669 & I \\
Port2 & -0.1070 & 0.2486 & -0.2947 & -0.4409 & -0.6491 & II \\
Port3 & -0.0933 & 0.1869 & -0.2753 & -0.4734 & -0.6558 & II \\
Port4 & -0.1768 & 0.1663 & -0.1341 & -0.4246 & -0.5967 & II \\
Port5 & -0.5528 & -0.3621 & -0.1614 & 0.0988 & -0.1377 & IV \\
\hline
\end{tabular}

Field investigations of five ports conform to analysis results of this study. Assessment indexes and assessment results were compared with assessment reports of Zhejiang Port and Navigation Authority to the five ports, thereby obtaining consistent results. Therefore, the port safety assessment based on entropy weight matter-element model is feasible and can provide decision references for port safety assessment and safety improvement.

\section{Conclusions}

For comprehensive and effective assessment of port safety, a port safety assessment index system was constructed on the basis of the $5 \mathrm{M}$ model. The port safety assessment model was designed by combining entropy weight method and matter-element theory. The following conclusions are drawn:

(1) The port safety assessment index system is constructed on the basis of the $5 \mathrm{M}$ model (man, machine, material, management, and milieu) and can comprehensively indicate practical safety management. The system is highly scientific.

(2) The weight setting of indexes shows that material factor presents the highest average weight and the highest influence on the port safety assessment result. Accident rate of goods and qualification rate of pollution control show the highest weights and are thus the most important indexes of port safety assessment.

(3) The port safety assessment model that combines entropy weight method and matter-element theory is feasible in actual cases. The entropy weight method can reduce human interference to index assignment. Matter-element theory can change assessment indexes from single determined value into interval value, thereby making the port safety assessment highly comprehensive.

In summary, the port safety assessment model based on entropy weight matter-element theory is an effective tool for evaluating port safety. The model is conducive to exploring safety problems in port production management and preventing safety accidents. This study emphasizes on safety assessment but does not discuss the improvement measures. Further studies can design improvement routes on the basis of the assessment results to improve the practicality of the study problem.

\section{Acknowledgements}

The study was supported by the National Natural Science Foundation of China (41501142); the Natural Science Foundation of Zhejiang Province (LY15D010003); the Postdoctoral Science Foundation of Jiangsu Province (1402116C).

Access article distributed under the terms of the Creative Commons Attribution Licence

\section{References}

1. Merkel, A., Holmgren, J., "Dredging the depths of knowledge: Efficiency analysis in the maritime port sector". Transport Policy, 60, 2017, pp.63-74.

2. Bichou, K., "Assessing the impact of procedural security on container port efficiency". Maritime Economics and Logistics, 13(1), 2011, pp.1-28.

3. Obhodas, J., Valkovic, V., Sudac, D., Matika, D., Pavic, I., Kollar, R., "Environmental security of the coastal seafloor in the sea ports and waterways of the Mediterranean region". Nuclear Instruments and Methods in Physics Research Section A: Accelerators, Spectrometers, Detectors and Associated Equipment, 619(1-3), 2010, pp.419-426.

4. Zhang, D., Yan, X. P., Yang, Z. L., Wall, A., Wang, J., "Incorporation of formal safety assessment and Bayesian network in navigational risk estimation of the Yangtze River". Reliability Engineering \& System Safety, 118(10), 2013, pp.93-105.

5. Hsu, W. K. K., "Ports' service attributes for ship navigation safety". Safety Science, 50(2), 2012, pp.244-252.
6. Yeo, G. T., Pak, J. Y., Yang, Z., "Analysis of dynamic effects on seaports adopting port security policy". Transportation Research Part A: Policy and Practice, 49, 2013, pp.285-301.

7. Motter, A. A., Santos, M., "The importance of communication for the maintenance of health and safety in work operations in ports". Safety Science, 96, 2017, pp.117-120.

8. Fabiano, B., Currò, F., Reverberi, A. P., Pastorino, R., "Port safety and the container revolution: A statistical study on human factor and occupational accidents over the long period". Safety Science, 48(8), 2010, pp.980-990.

9. Antão, P., Calderón, M., Puig, M., Michail, A., Wooldridge, C., Darbra, R. M., "Identification of Occupational Health, Safety, Security (OHSS) and Environmental Performance Indicators in port areas". Safety Science, 85, 2016, pp.266-275.

10. Pak, J. Y., Yeo, G. T., Oh, S. W., Yang, Z., "Port safety evaluation from a captain's perspective: The Korean experience". Safety Science, 72, 2015, pp.172-181. 
11. Yang, Z., Ng, A. K. Y., Wang, J., "A new risk quantification approach in port facility security assessment". Transportation Research Part A: Policy and Practice, 59(1), 2014, pp.72-90.

12. Cetin, G., Demirciftci, T., Bilgihan, A., "Meeting revenue management challenges: Knowledge, skills and abilities". International Journal of Hospitality Management, 57, 2016 , pp.132-142.

13. Souza, A. S., Oberauer, K., "Time to process information in working memory improves episodic memory". Journal of Memory and Language, 96, 2017, pp.155-167.

14. Tretsiakova-McNally, S., Maranne, E., Verbecke, F., Molkov, V., "Mixed e-learning and virtual reality pedagogical approach for innovative hydrogen safety training of first responders". International Journal of Hydrogen Energy, 42(11), 2017, pp.75047512.

15. Chen, H. C., Liu, S. M., "Should ports expand their facilities under congestion and uncertainty?" Transportation Research Part B: Methodological, 85, 2016, pp.109-131.

16. Yang, Y. C., Lin, C. L., "Performance analysis of cargo-handling equipment from a green container terminal perspective". Transportation Research Part D: Transport and Environment, 23(3), 2013, pp.9-11.

17. Uğurlu, Ö., "Analysis of fire and explosion accidents occurring in tankers transporting hazardous cargoes". International Journal of Industrial Ergonomics, 55, 2016, pp.1-11.

18. Qiu, X., Lam, J. S. L., Huang, G. Q., "A bilevel storage pricing model for outbound containers in a dry port system". Transportation Research Part E: Logistics and Transportation Review, 73, 2015, pp. 65-83.
19. Stroh, R., Bect, J., Demeyer, S., Fischer, N., Marquis, D., Vazquez, E., "Assessing fire safety using complex numerical models with a Bayesian multi-fidelity approach”. Fire Safety Journal, 91, 2017, pp. 1016-1025.

20. Guo, H., Yu, Y., Xiang, T., Li, H., Zhang, D., "The availability of wearable-device-based physical data for the measurement of construction workers' psychological status on site: From the perspective of safety management". Automation in Construction, 82, 2017, pp.207-217.

21. Dorasamy, M., Raman, M., Kaliannan, M., "Integrated community emergency management and awareness system: A knowledge management system for disaster support". Technological Forecasting and Social Change, 121, 2017, pp.139-167.

22. Bazgosha, A., Ranjbar, M., Jamili, N., "Scheduling of loading and unloading operations in a multi stations transshipment terminal with release date and inventory constraints". Computers \& Industrial Engineering, 106, 2017, pp.20-31.

23. Hu, Y., Yao, L., Cheng, Z., Wang, Y., "Long-term atmospheric visibility trends in megacities of China, India and the United States". Environmental Research, 159, 2017, pp.466-473.

24. Valdor, P. F., Gómez, A. G., Puente, A., "Environmental risk analysis of oil handling facilities in port areas. Application to Tarragona harbor (NE Spain)". Marine Pollution Bulletin, 90(1-2), 2015, pp.78-87.

25. Trifunović, A., Pešić, D., Čičević, S., Antić, B., "The importance of spatial orientation and knowledge of traffic signs for children's traffic safety". Accident Analysis \& Prevention, 102, 2017, pp.8192.

26. Chen, Q., Wu, W., Blanckaert, K., Ma, J., Huang G., “Optimization of water quality monitoring network in a large river by combining measurements, a numerical model and matter-element analyses". Journal of Environmental Management, 110, 2012, pp.116-124. 